\title{
FABLAB PRONTO3D: APRENDENDO COM A PRÁTICA
}

\author{
Regiane Trevisan Pupo \\ Universidade Federal de Santa Catarina \\ regipupo@gmail.com
}

\begin{abstract}
Resumo
O recente desenvolvimento e utilização de técnicas de fabricação digital para a arquitetura, design, engenharias, construção, dentre outras, têm causado mudanças de impacto no processo de projeto desde seu início até sua construção final. Novos métodos de construção estão sendo desenvolvidos com o uso dessas novas técnicas, abrindo um leque de possibilidades dificilmente alcançadas anteriormente. Espaços nomeados como FABLAB's hoje, oferecem uma gama de técnicas, procedimentos e equipamentos que proporcionam a execução de modelos, protótipos ou elementos finais em diferentes graus de fidelidade. Este artigo mostra as possibilidades e atividades executadas, com base nestas tecnologias, no PRONTO3D - Laboratório de Prototipagem e Novas Tecnologias Orientadas ao 3D, na UFSC, que faz parte da Rede PRONTO3D, no estado de Santa Catarina, desde 2013.
\end{abstract}

Palavras-chave: Fabricação Digital. Materialização. Prática Projetual.

\section{FABLAB PRONTO3D: LEARNING WITH PRACTICE}

\begin{abstract}
The recent development and use of digital fabrication techniques for architecture, product design, engineering, construction, among many others, has caused impact changes on design processes since its beginning until final construction. New construction methods have been developed with the use of those new techniques, spreading many ways of possibilities hardly achieved before. Nowadays, spaces called FABLABs offer a range of procedures and equipment that provide the manufacture of scale models, prototypes or final elements in different fidelity degrees. This paper shows the possibilities and activities being implemented, with the use of technology, at PRONTO3D - Prototyping and New 3D Oriented Technology Laboratory, at UFSC, that belongs to PRONTO3D Network Labs, in Santa Catarina State, since 2013.
\end{abstract}

Keywords: Digital Fabrication. Materialization. Design Process.

\section{FABLAB PRONTO3D: APRENDIENDO CON LA PRÁCTICA}

\section{Resumen}

El reciente desarrollo y utilización de técnicas de fabricación digital para la arquitectura, diseño, ingenierías, construcción, entre otras, han causado cambios de impacto en el proceso de diseño desde su inicio hasta su construcción final. Los nuevos métodos de construcción se están desarrollando con el uso de estas nuevas técnicas, abriendo un abanico de posibilidades jamás alcanzadas anteriormente. Espacios nombrados como FABLAB's hoy, ofrecen una gama de técnicas, procedimientos y equipos que proporcionan la ejecución de modelos, prototipos o elementos finales en diferentes grados de fidelidad. Este artículo muestra las posibilidades y actividades ejecutadas, basándose en estas tecnologías, en el PRONTO3D - Laboratorio de Prototipado y Nuevas Tecnologías Orientadas al 3D, en la UFSC, que forma parte de la Red PRONTO3D, en el estado de Santa Catarina, desde 2013.

Palavras clave: Digital Manufacturing. Materialización. Práctica Proyectuala. 
FABLAB PRONTO3D: aprendendo com a prática

\section{INTRODUÇÃO}

Desde a introdução das ferramentas computacionais em processos de projeto de arquitetura, design e engenharia, nos idos da década de 1980, que uma verdadeira revolução na maneira de pensar, criar, produzir e fabricar vem se completando a cada década. Os primeiros sistemas CAD (Computer Aided Design - Computador Auxiliando o Projeto) tinham a nobre missão de representação bidimensional (2D) e modelagem tridimensional (3D), nas quais as visualizações eram a grande justificativa do uso desta nova tecnologia. Por vários anos, as práticas projetuais que envolviam o uso de maquete ou modelos físicos em escala reduzida, foram dando lugar para passeios virtuais e maquetes eletrônicas com aplicação de texturas, cenários, vegetação e pessoas, que enchiam os olhos de estudantes, profissionais e clientes. Com isso, as habilidades de exploração e entendimento dos projetos eram rapidamente assimiladas e melhoradas e a execução de modelos físicos se tornava cada vez mais em desuso.

Entretanto, frente à necessidade de edição ou manipulação do projeto sendo demonstrado, os processos de rearranjo para novas visualizações, frequentemente, se tornavam morosos, visto a falta de 1) suporte e interação, por parte dos software CAD e 2) da experiência em programação dos profissionais. Além disso, a conexão 2D-3D-2D não era tão suportada nem facilitada; os software eram mais pranchetas eletrônicas do que propriamente um auxilio projetual.

Já no início do novo século, a evolução do software CAD, em termos tecnológicos e funcionais, enveredou por caminhos, por pura necessidade de seus usuários, que levaram ao uso do Design Paramétrico, em que o controle do usuário é mais interativo, direto e consciente. Os software já não são mais criados exclusivamente por programadores que tem pouca, ou as vezes nenhuma, experiência em projeto, qualquer que seja seu campo de atuação, arquitetura, design, engenharia. A evolução dos software fez com que o profissional destas áreas passasse a programar as suas próprias necessidades projetuais, tornando seu o controle das ações.

Os arquitetos, por exemplo, utilizam software na criação de formas complexas que contêm inúmeras informações e o potencial que estas novas tecnologias trazem à produção e ao gerenciamento de projetos tem revolucionado a forma como se produz, avalia, fabrica e constrói arquitetura. Contudo, isso levou a um momento de reavaliação dos mecanismos inerentes a essa utilização desenfreada (Pupo, 2009). Historicamente, desenhos bidimensionais foram o meio de comunicação em projetos de arquitetura, engenharia e design industrial por muito tempo. Mesmo assim, não são mais considerados como soluções que possam garantir uma compreensão espacial, tanto na fase conceitual quanto na de representação. A representação tridimensional e o modelo 
FABLAB PRONTO3D: aprendendo com a prática

físico proporcionam um maior êxito nessa comunicação, estabelecendo proporcionalidades, perspectivas e funcionalidades inerentes ao projeto, que talvez não pudessem ser evidenciadas em uma representação virtual.

Segundo Pallasma (2013, p.15), em diversas áreas do conhecimento, a "consciência humana é uma consciência corporificada", o que faz o ser humano estar conectado ao mundo por meio de todos os sentidos. Para o autor, juntamente à arquitetura predominante aos olhos, o tato é entendido como experimentação e compreensão do espaço em que se habita, onde toda a experiência tátil é multissensorial. Complementa ainda que, nestes últimos tempos de informatização, o tato é o sentido mais esquecido, porém é o modo sensorial que integra a experiência de mundo com a individualidade.

\footnotetext{
"Até mesmo na era do projeto assistido por computador (CAD) e das maquetes eletrônicas, os modelos ou as maquetes tradicionais são recursos incomparáveis no processo de projeto de um desenhista de produto ou arquiteto. O modelo físico ou a maquete tridimensional falam com nossas mãos e corpos de maneira tão poderosa quanto nossos olhos, e o próprio processo de construir um modelo ou uma maquete simula o processo da construção da obra final" (PALLASMA, 2011, p.60).
}

Assim, a materialização da forma auxilia no pensamento projetual em sua plena totalidade espacial (PALLASMA, 2011) constituindo-se em uma realidade tátil e multissensorial da imaginação. É, sem dúvida, uma experiência que vem embutida de uma intimidade que não pode ser alcançada por meio de maquetes eletrônicas ou mesmo qualquer simulação computadorizada, pelo simples fato de, nestes casos, ainda se ter a superfície do monitor como anteparo tátil.

Portanto, aliando as novas formas de Design Paramétrico às novas tecnologias de materialização da forma, arquitetos, designers e engenheiros têm desenvolvido novos "vocabulários" não somente para a produção final dos produtos, mas também para modelos físicos (modelos ou maquetes), graças a uma variedade de ferramentas e técnicas que têm surgido para completar as tradicionais, potencializando todo o processo de projeto. A fabricação digital é uma delas. Diversas técnicas para a produção de modelos físicos se utilizam da modelagem 3D, produzida com o avanço de software, na transformação do desenho visualizado no computador para a maquete física. A fabricação digital, hoje, é uma grande aliada para uma melhor compreensão espacial do projeto, com tecnologias que se utilizam de matérias primas como gesso, resinas, plásticos, entre outros, para a confecção de modelos, elementos construtivos ou peças finais, em prazos mínimos se comparados às técnicas tradicionais (PUPO, 2009). 
FABLAB PRONTO3D: aprendendo com a prática

A maioria dos profissionais em arquitetura, design e engenharia já incorporou o CAD (Computer Aided Design) como ferramenta de desenho, hoje visto como procedimento comum até mesmo onde muitas vezes não seria necessário. Seu extensivo uso já extrapolou a simples barreira da representação e novas formas de aplicação têm sido exploradas. O CAM (Computer Aided Manufacturing - Computador Auxiliando a Manufatura), que vem associado à fabricação digital, converge um maquinário de peso destinado à execução de elementos construtivos para serem encaminhados diretamente à obra. Esse tipo de equipamento, principalmente as máquinas de controle numérico (CNC - Computer Numeric Control), por muito tempo de uso quase exclusivo da engenharia mecânica, é hoje amplamente utilizado em outras áreas, como responsável pela produção de fôrmas ou elementos construtivos que irão compor fisicamente o projeto idealizado.

\section{OS FABLAB's}

Diante de toda esta diversidade de possibilidades e novas interações para o processo projetual, bem como na representação da forma, que um novo conceito de aproximação da tecnologia aplicada vem sendo explorado e rapidamente utilizado e assimilado no mundo todo. São os chamados FabLab’s (acrônimo para Fabrication Laboratories - Laboratórios de Fabricação Digital) que são espaços munidos de alta tecnologia para a materialização da forma, mas acessíveis para qualquer camada da sociedade, acadêmica ou não. Com acesso à informação e meios de invenção através da fabricação digital, os FabLabs são laboratórios que possibilitam a todos transformarem suas ideias e projetos em realidade.

Nascido como um projeto de extensão do Professor Neil Gershenfeld, diretor do Center for Bits and Atoms do Massachusetts Institute of Technology (MIT), nos Estados Unidos, os FabLabs constituem atualmente uma comunidade internacional, formada por mais de mil laboratórios espalhados em centenas de países, cujo objetivo é compartilhar o conhecimento adquirido nas experiências de cada unidade. Tais laboratórios também compartilham equipamentos e processos, além de arquivos digitais e soluções, formando assim uma verdadeira rede para o intercâmbio de ideias.

Cada FabLab possui um foco diferente. Existem aqueles com um olhar mais voltado para a solução de problemas básicos locais, trabalhando em projetos conjuntos com governos e universidades, enquanto outros tem um viés mais prático, provendo acesso livre às máquinas e equipamentos, para que cada indivíduo desenvolva seu próprio projeto pessoal. Os laboratórios são certificados pelo MIT e preparados para oferecer apoios operacional, educativo, técnico e 
logístico, para além do que está disponível num laboratório, disponíveis como um recurso da comunidade, oferecendo acesso para indivíduos, bem como agendamento de grupos de qualquer faixa etária. Os FabLabs dispõem de um conjunto de equipamentos (Figura 1) em evolução e com capacidade para fazer (quase) qualquer coisa, permitindo que ideias e projetos sejam partilhados na rede.

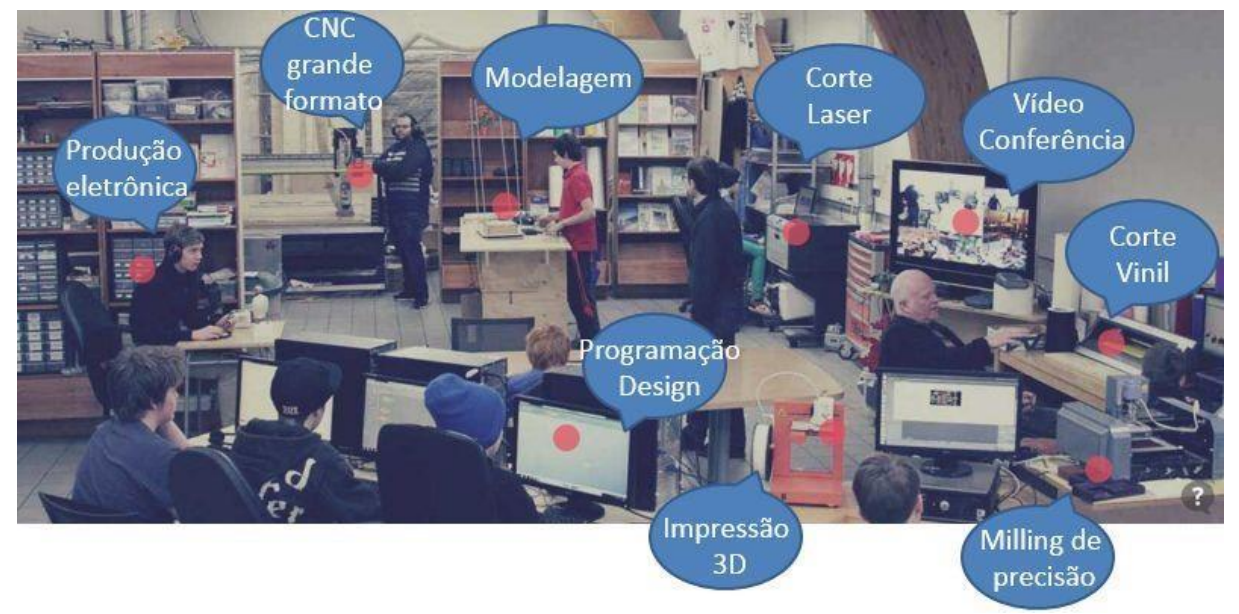

Ilustração 1 - Configuração básica de um FabLab Fonte: Adaptação FabFoundation (2017)

\section{A REDE PRONTO3D}

Criada em 2013, a Rede PRONTO3D - Laboratórios de Prototipagem e Novas Tecnologias Orientadas ao 3D - é uma rede de laboratórios de fabricação digital que visa a estruturação de centros estrategicamente localizados no estado de Santa Catarina, atualmente com polos nas cidades de Lages, Criciúma, Chapecó e Florianópolis. Com apoio e suporte da FAPESC e do FINEP para sua concretização, cada laboratório iniciou, em 2013, suas atividades com uma impressora 3D, uma Reuter CNC de grande porte e uma cortadora laser. Com o objetivo de atender a mais variada gama de cursos do meio acadêmico, nas áreas do ensino, pesquisa e extensão, bem como a sociedade em geral, as atividades abrangem todas as áreas que envolvam criação, desenvolvimento e produção de modelos, protótipos, maquetes e produtos em escala real, com o uso de tecnologia de ponta, auxiliando as diferentes etapas do processo de projeto.

A missão da Rede PRONTO3D inclui 5 pontos fundamentais, a saber: 1) Oferecer a seus pesquisadores uma infraestrutura apropriada, 2) Capacitar uma equipe de facilitadores para a disseminação da tecnologia aplicada, 3) Oferecer incentivos em forma de bolsas e estágios, 4) Executar trabalho efetivamente eficiente e 5) Proporcionar um trabalho colaborativo entre toda a rede. Visando alcançar a plenitude nas atividades às quais a rede se propõe, os laboratórios da Rede PRONTO3D são espaços munidos de características como a eficiência, a versatilidade, a colaboração, a criatividade e o lúdico, que formam seu DNA. 
FABLAB PRONTO3D: aprendendo com a prática

O polo de Florianópolis, que está localizado na UFSC, tem a gestão do curso de Design e já atendeu cursos como, além do Design, Arquitetura, Engenharia de Materiais, Mecânica, Elétrica, Museologia, Fisiologia, Administração, dentre outros, nas mais diversas formas de atuação. Hoje, dentre os equipamentos e tecnologias disponíveis, o laboratório conta com 4 impressoras 3D, uma cortadora laser, uma Reuter $\mathrm{CNC}$ de grande formato $(3 \times 2 \mathrm{~m})$, uma Reuter de subtração e circuito impresso e um equipamento de termoformagem, este desenvolvido no próprio laboratório. Em janeiro de 2016, o PRONTO3D Florianópolis foi certificado pelo MIT como um FabLab e passa a fazer parte da rede internacional de laboratórios de fabricação digital.

\section{MATERIAIS E MÉTODOS}

Nesta seção serão identificados e descritos alguns dos trabalhos desenvolvidos especificamente do Polo de Florianópolis, na UFSC, bem como algumas de suas atividades nos campos do ensino, pesquisa e extensão.

A possibilidade de incorporar esses novos meios de produção na pesquisa e desenvolvimento de novos produtos traz novas perspectivas de avanço e inovação no aprendizado e assimilação do conhecimento. A mudança de paradigma do processo de aprendizagem é entendida e baseada em pesquisa e experimentação. A pedagogia de Papert (1991), por exemplo, difere da pedagogia tradicional quando 1) enfatiza o aprender e não o ensinar; 2) incentiva o desenvolvimento pessoal do aluno por meio da construção do conhecimento através da pesquisa e não simplesmente a transmissão de conhecimento do professor para o aluno; e 3) aplica o aprender fazendo (hands on) em suas atividades. Esse tipo de raciocínio exploratório deve estar presente na mente de jovens pesquisadores que tenham como objetivo explorar novas possibilidades e assim chegar ao desenvolvimento criativo de produtos e processos inovadores. $\mathrm{E}$ esta é a dinâmica das inúmeras atividades do PRONTO3D: a experimentação (Figura 2). A chamada popularmente "mão na massa" faz com que a assimilação de conceitos, conteúdos, critérios e limites da matéria seja explorada de forma prática e lúdica. 

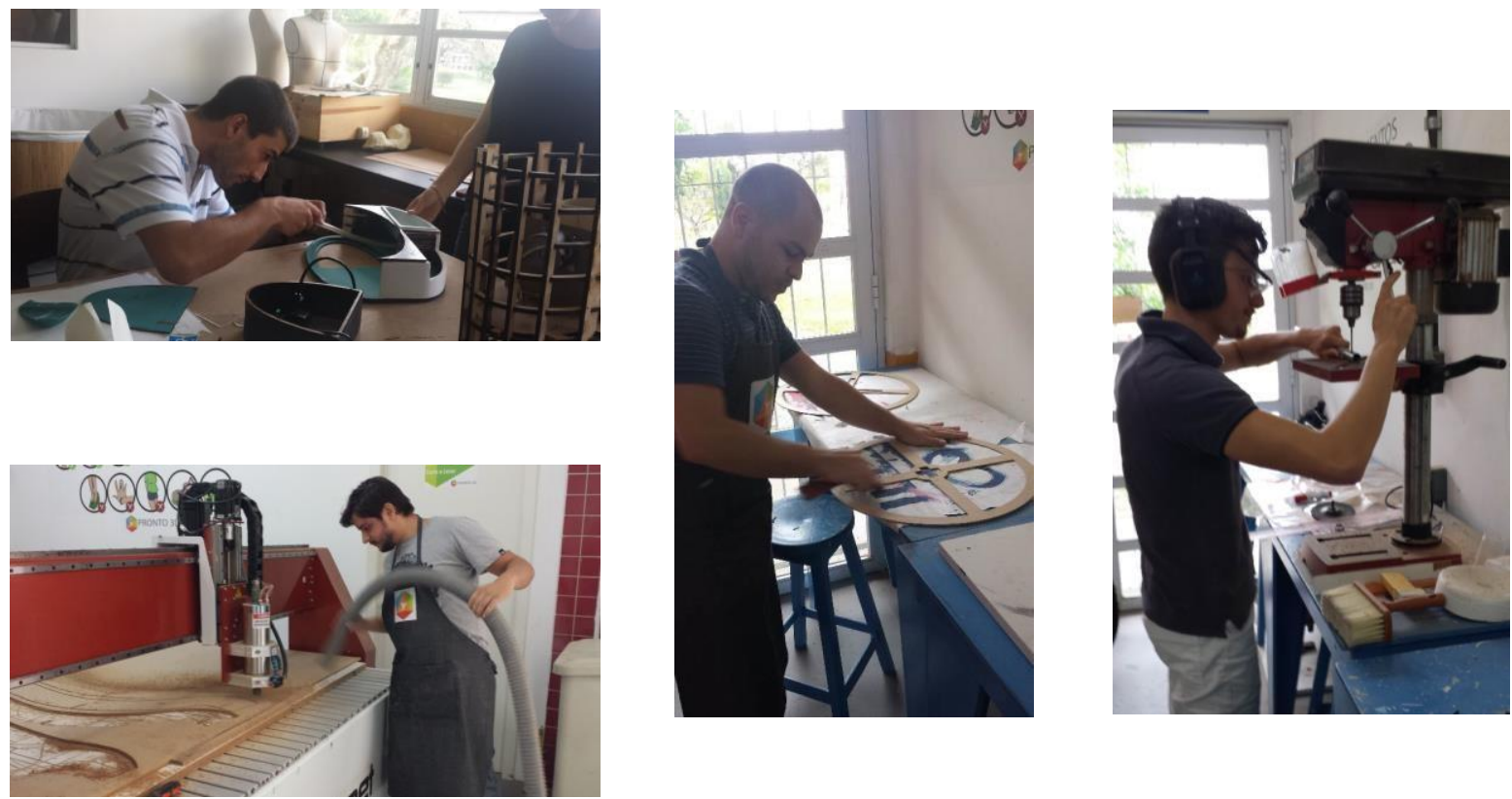

Figura 2 - Alunos na prática de suas pesquisas Fonte: Acervo PRONTO3D

A criatividade é explorada com o auxílio das tecnologias disponíveis no FABLAB, descritas a seguir.

\section{CORTE LASER}

Sem dúvidas, é a tecnologia mais utilizada e procurada por alunos e pesquisadores pela facilidade de uso, por utilizar desenhos bidimensionais (que serão posteriormente montados após os cortes) e por aceitar uma gama muito grande de tipos de materiais. A figura 3 ilustra alguns trabalhos idealizados por alunos do curso de design em que o tema de projeto era "luminárias", enfatizando a investigação de materiais que pudessem ser usados nesta tecnologia, bem como aplicadas nos elementos de iluminação.
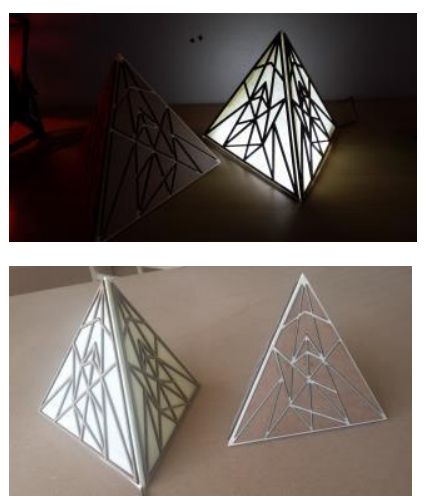
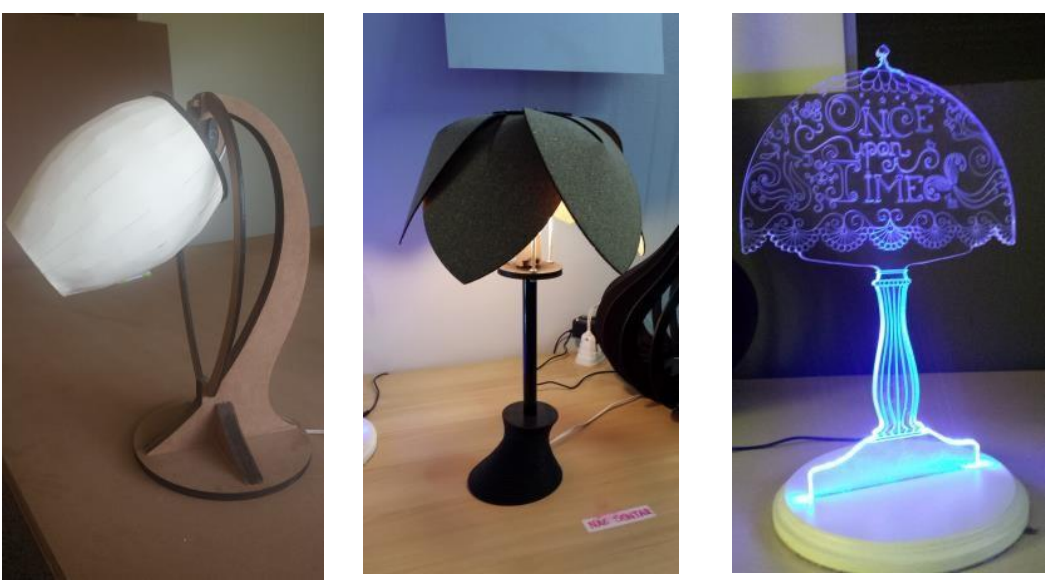

Figura 3 - Trabalhos em corte laser Fonte: Acervo PRONTO3D 
Ao mesmo tempo, a exploração do papelão em suas variadas gramaturas e texturas pôde ser experimentada na idealização de modelos de superfícies de assento (pufes), em escala reduzida, com técnicas de projetação que conseguem explorar a forma, por meio de “interlocking", uma técnica que encaixa as fatias de papelão previamente projetadas e distribuídas por software especializado (123DMake) de acordo com a espessura da matéria prima. A figura 4 mostra alguns exemplos desta técnica, desenvolvidos no PRONTO3D.
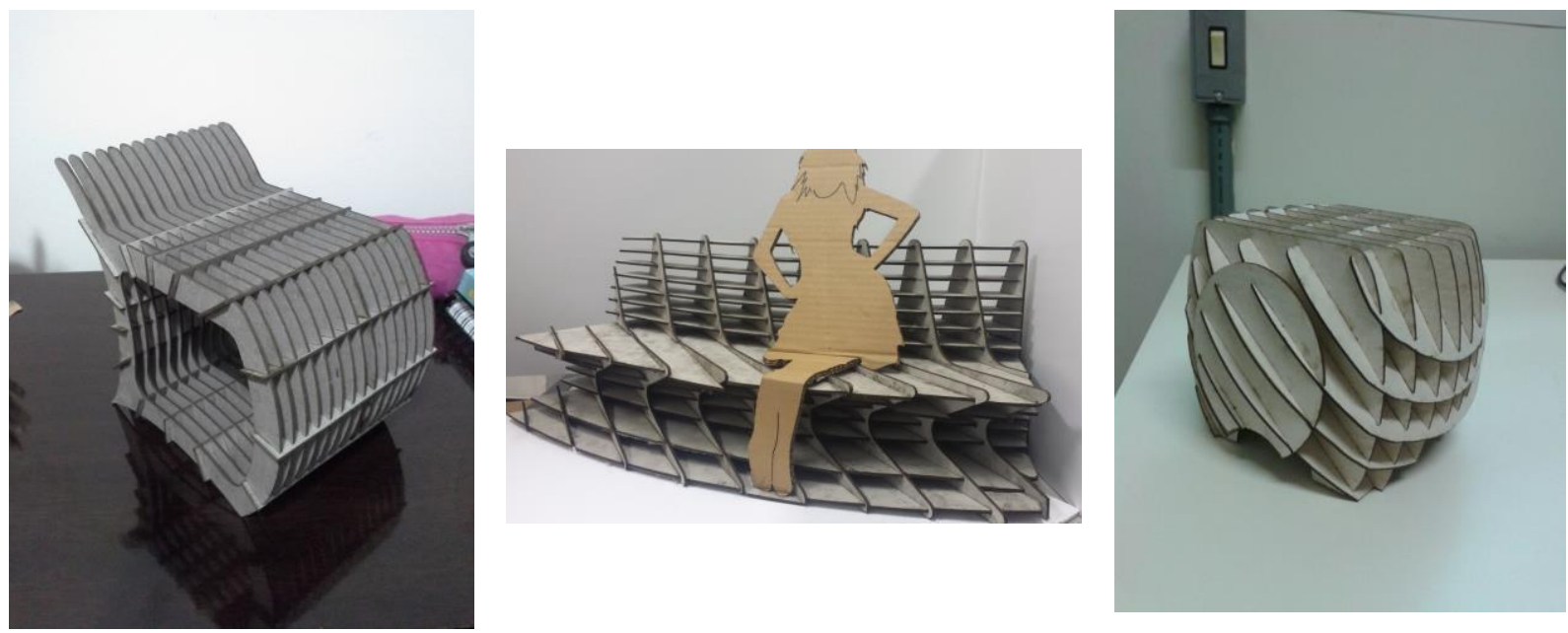

Figura 4: Trabalhos com a técnica Interlocking e corte laser em papelão Fonte: Acervo PRONTO3D

$\mathrm{Na}$ área da moda e modelagem, a exploração no uso de tecidos que tivessem um desempenho favorável para este fim, utilizando a cortadora laser como ferramenta de projeto e proposição final, pôde ser testado em modelos de tamanho real (Figura 5).
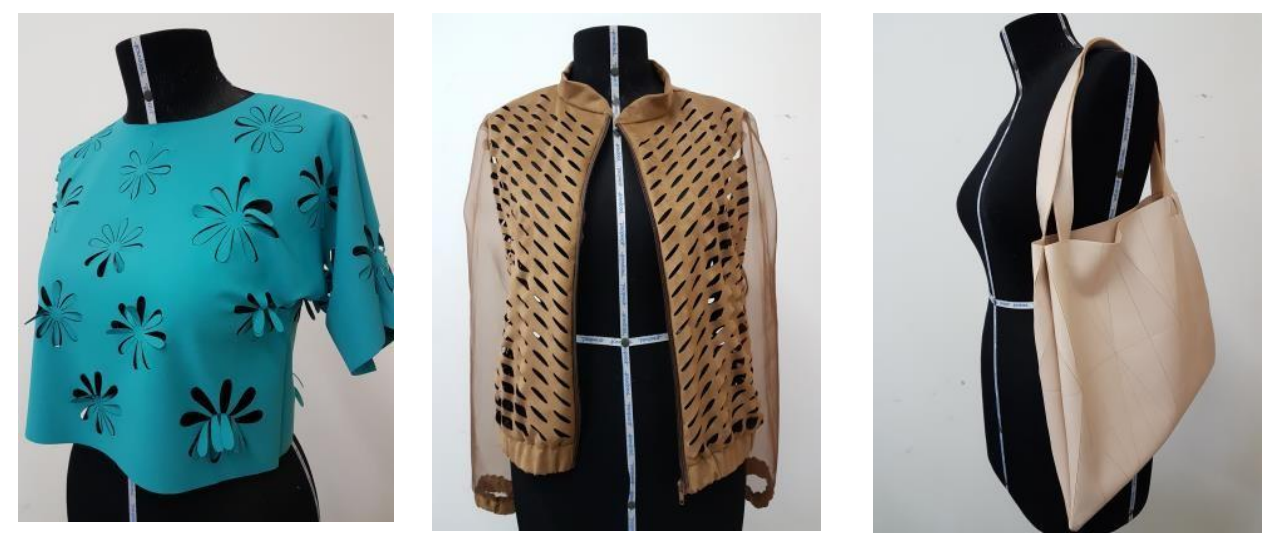

Figura 5: Protótipos finais de modelagem com corte laser

Fonte: Acervo PRONTO3D

\section{IMPRESSÃO 3D}

Há uma diversidade de tecnologias de impressão 3D hoje, as chamadas técnicas aditivas, que segmentam seu uso para a execução de modelos e protótipos em escala reduzida e tem a 
capacidade de imprimir um modelo tridimensionalmente, advindo de um arquivo digital. São técnicas com equipamento que utilizam diferentes materiais; dentre estas tecnologias podese destacar 1) Sinterização Seletiva a Laser (SLS) que utiliza resina em pó sinterizada a laser, 2) Esteriolitgrafia (SLA) que utiliza resina líquida sinterizada a laser, 3) 3DP que utiliza pó de gesso sinterizada com Binder (cola) e 4) Fused Deposition Modeler (FDM) que usa termoplásticos (como PLA - Ácido polilático e ABS - Acrilonitrila butadieno estireno). A técnica mais utilizada atualmente, devido ao preço acessível dos equipamentos e suprimentos, é a FDM, que utiliza filamento de termoplásticos que são derretidos e sobrepostos em camadas, formando o objeto. O PRONTO3D possui três equipamentos que utilizam esta tecnologia e alguns trabalhos desenvolvidos podem ser visualizados na figura 6 .
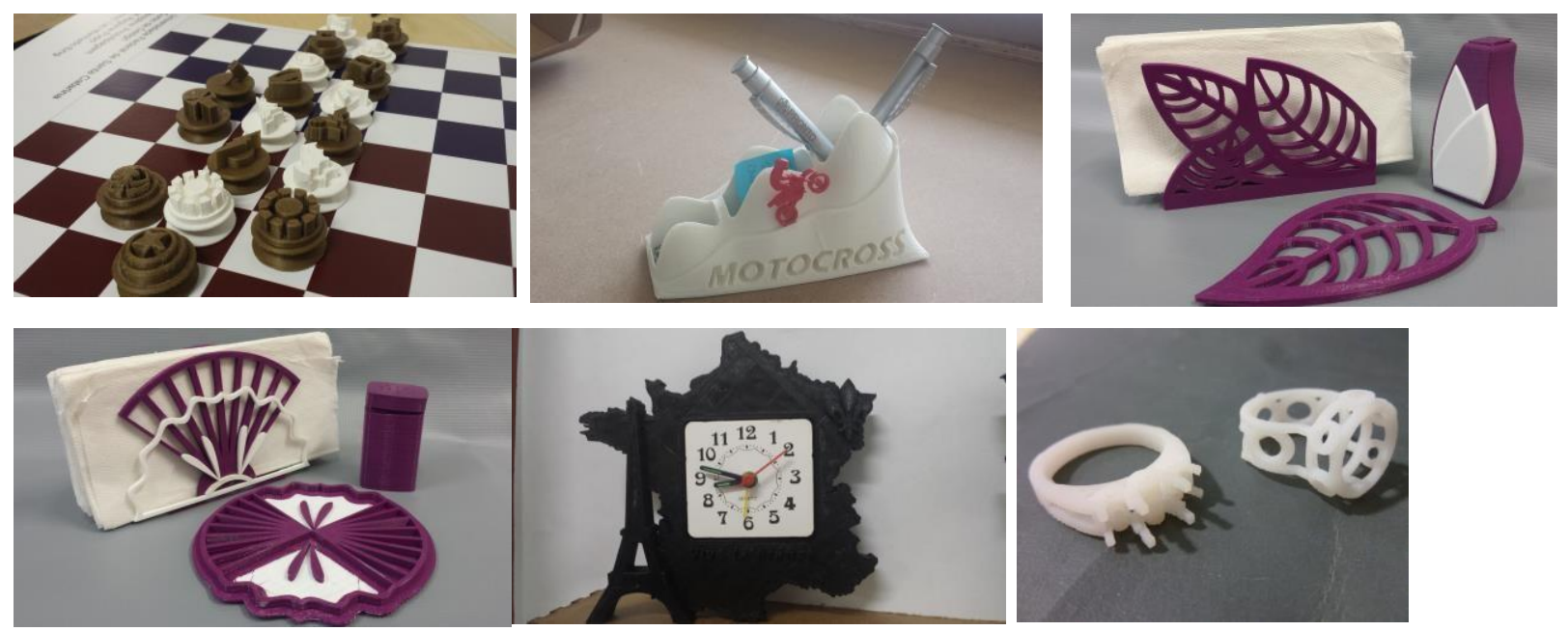

Figura 6 - Trabalhos em impressão 3D (FDM) Fonte: Acervo PRONTO3D

\section{CNC (CONTROL NUMERIC CONTROL)}

As tecnologias subtrativas são aquelas que desbastam ou perfilam materiais como madeira, poliuretano, isopor, alumínio, dentre outras, por meio de fresas a partir de desenhos digitais. A materialização da forma se dá, aqui, com a retirada de material até que a forma seja obtida, por equipamentos de CNC os quais são controlados numericamente (coordenadas $\mathrm{x}$, y e z). Estes equipamentos são considerados de grande porte, com dimensões e número de eixos variados. O PRONTO3D possui dois equipamentos deste tipo, um com dimensões $2 \mathrm{x}$ $3 \mathrm{~m}$ em que se tem a possibilidade de obter protótipos em escala real ou mesmo fôrmas para posterior concretagem, e outro para a obtenção de placas de circuito impresso. A figura 7 mostra alguns trabalhos em escala real produzidos no laboratório. 

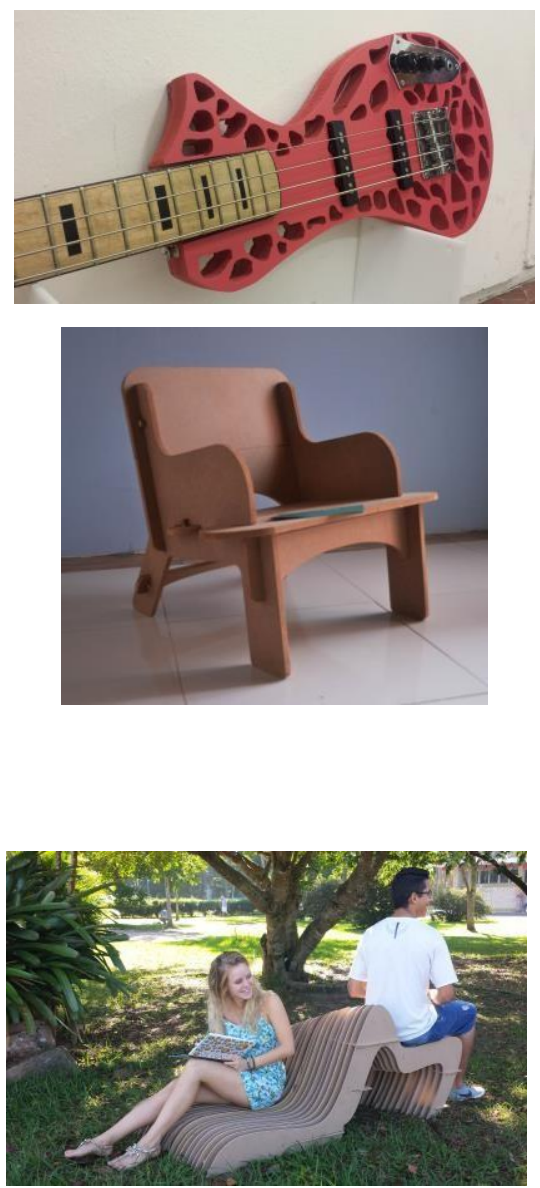
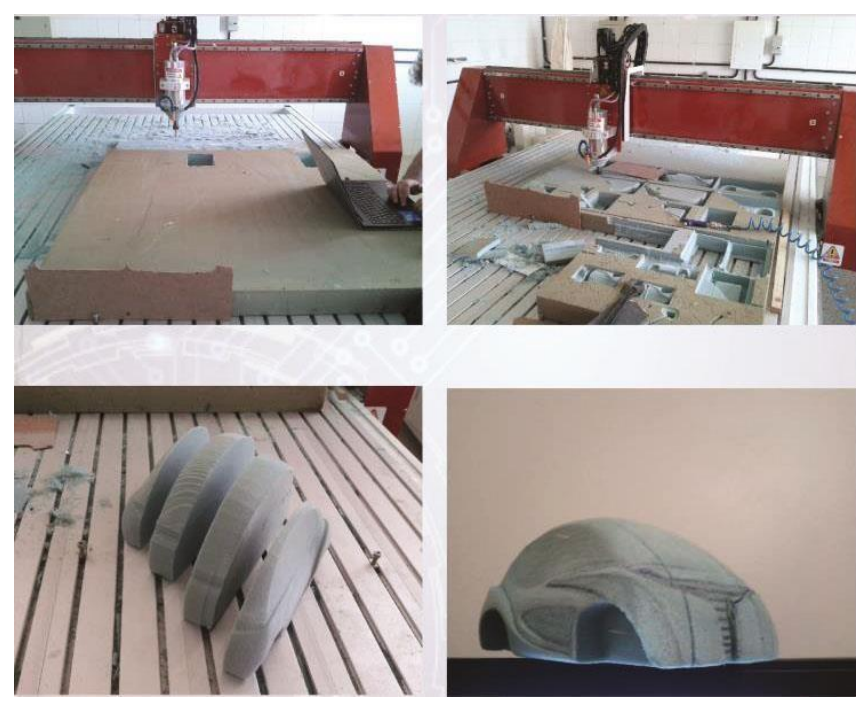

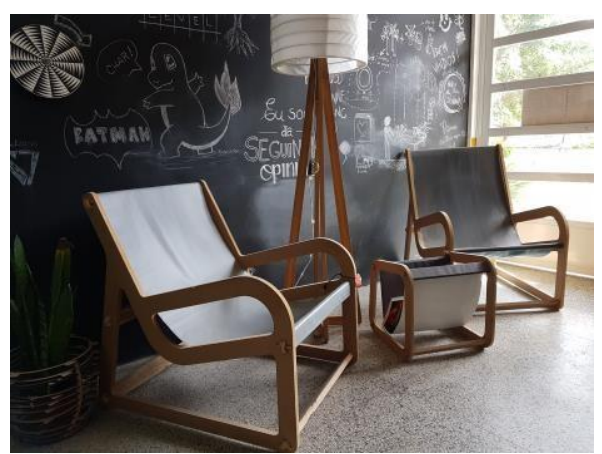

Figura 7 - Trabalhos desenvolvidos no PRONTO3D em CNC

Fonte: Acervo PRONTO3D

\section{RESULTADOS E ANÁLISES}

Todas as tecnologias, atividades e possibilidades aqui apresentadas são absorvidas em diversas práticas de extensão promovidas pelo PRONTO3D, em Florianópolis. Dentre elas, destaca-se o PRONTO KIDS, que conta com a execução de oficinas, realizadas no laboratório, para crianças entre 6 e 12 anos de idade, em parceria com escolas da educação básica. Com o intuito de mostrar o uso da tecnologia digital para crianças, as atividades visam a disseminação da tecnologia aliada à criatividade tão aflorada nesta idade, que vem compartilhada à sede de aprendizado e fácil assimilação. As primeiras atividades desta categoria, com uma turma de 15 alunos do Colégio de Aplicação da UFSC, as crianças tiveram contato com a tecnologia de corte laser na execução de elementos que identificassem o aprendizado anteriormente obtido em sala de aula. Na primeira edição, ocorrida em maio de 2016, os alunos, em fase de alfabetização, tinham o desafio de montar um brinquedo, em forma de dinossauro, previamente cortado na tecnologia laser, em que suas peças tinham marcadas (também em laser) a sequência do alfabeto 
que deveriam ser respeitadas para o sucesso da montagem. A atividade foi lúdica, interativa, participativa e informativa no sentido de incentivar o uso consciente da tecnologia para a materialização da forma (Figura 8).
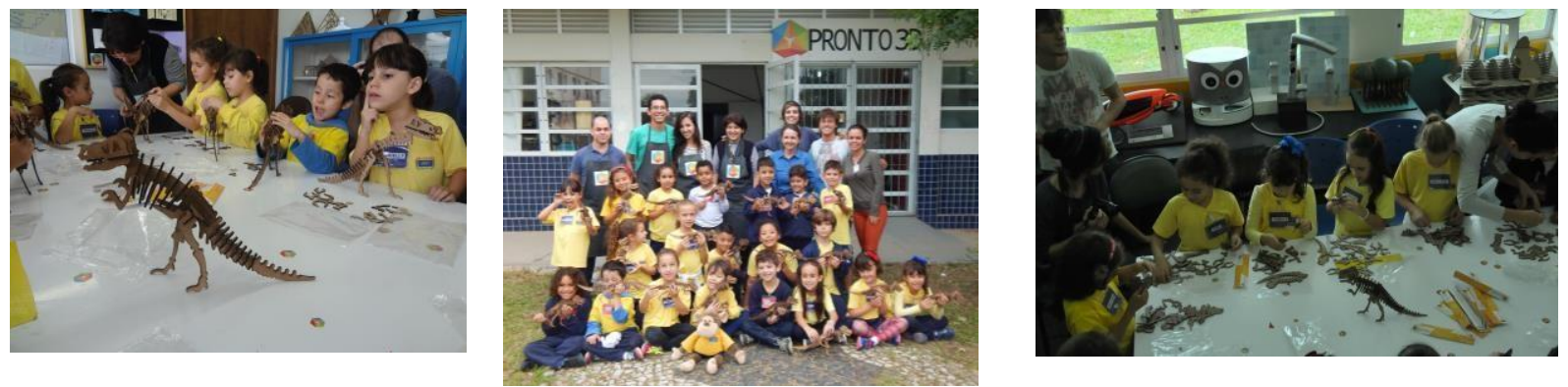

Figura 8 - PRONTOKIDS

Fonte: Acervo PRONTO3D

Seguindo os mesmos moldes, mais duas atividades com crianças foram executadas no laboratório, com temas diferenciados, a conscientização da dengue e um estudo de animais em extinção. No primeiro, os alunos também tiveram contato com a tecnologia de corte laser na montagem de uma libélula (Figura 9) e na segunda, a tecnologia abordada foi a impressão 3D, em que os alunos tiveram a oportunidade de ver materializados seus próprios desenhos bidimensionais (Figura 10) em objetos tridimensionais.
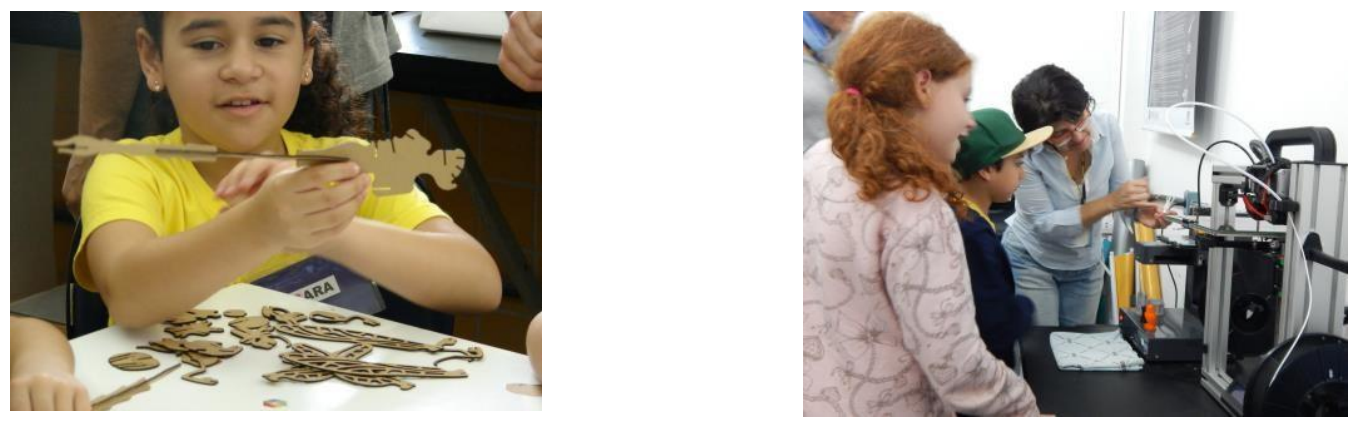

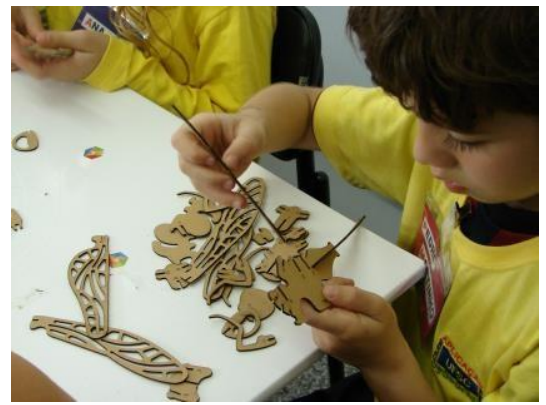

Figura 9 - PRONTOKIDS Fonte: Acervo PRONTO3D

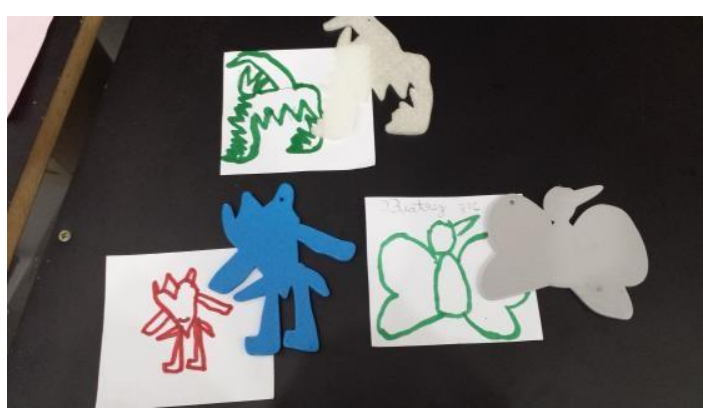

Figura 10 - PRONTOKIDS Fonte: Acervo PRONTO3D 
FABLAB PRONTO3D: aprendendo com a prática

As atividades de extensão no PRONTO3D não se resumem às aqui descritas, mas expandem para públicos diversificados, com interesses dos mais variados, mas sempre com o foco no aprender fazendo, direcionando para que a materialização da forma seja uma aliada na compreensão projetual, espacial e cognitiva.

Desde o início de suas atividades em Florianópolis, o laboratório já atendeu mais de 600 trabalhos acadêmicos, atende a comunidade não acadêmica por meio de projetos de extensão, em programas de capacitação e trabalhos de conscientização do uso de novas tecnologias em atividades comuns, com o foco nas tecnologias de fabricação e ainda, a cada semestre, oferece espaço para cerca de 15 bolsistas de iniciação cientifica, bolsas PIBIC e PIBIT, estágio obrigatório ou mesmo voluntários cujas pesquisas permeiam a aplicação das tecnologias de fabricação digital.

\section{CONSIDERAÇÕES FINAIS}

As atividades e trabalhos descritos neste artigo ilustram a dinâmica de aprendizado e assimilação de conteúdo aplicados no laboratório, em que o "aprender fazendo" é requisito primordial na integração da tecnologia de materialização da forma com o processo de criação projetual. O entendimento da tecnologia como nova ferramenta de trabalho e apoio à criação de ideias, soluções e inovação projetual, traz novas frentes de trabalho, com qualidade, inovação, soluções criativas, bem como facilita na prática do projeto colaborativo, encurtando caminhos e fronteiras da inovação.

\section{REFERÊNCIAS}

PALLASMA, Juhani. As Mãos Inteligentes: A sabedoria Existencial e Corporalizada na Arquitetura. Porto Alegre: Bookman, 2011. 76 p.

PALLASMA, Juhani. Os Olhos da Pele: A arquitetura e os sentidos. Porto Alegre: Bookman, 2013. 160 p.

PAPERT, S. Mindstorms: Children, Computers, and Powerful Ideas. N.Y.: Basic Books, 1980.

PAPERT, S. Situating Constructionism. Ablex Publishing Corporation. Edited by Idit Harel and Seymour Papert, 1991. 
FABLAB PRONTO3D: aprendendo com a prática

PUPO, Regiane. Inserção da prototipagem e fabricação digitais no processo de projeto: um novo desafio para o ensino da arquitetura. 2009. 260 f. Tese (Doutorado em Engenharia Civil). Faculdade de Engenharia Civil, Arquitetura e Urbanismo. Universidade Estadual de Campinas, São Paulo, 2009. Disponível em: $<$ http://home.fa.utl.pt/ progfabarq/tese.pdf $>$.

OXMAN, Rivka. Thinking difference: Theories and models of parametric design thinking, Design Studies (2017), http://dx.doi.org/10.1016/j.destud.2017.06.001 